\title{
PRODUÇÃO DE MUDAS DE GIRASSOL ORNAMENTAL E SEU DESENVOLVIMENTO EM VASOS UTILIZANDO COMO SUBSTRATO O GONGOCOMPOSTO
}

\author{
${ }^{1}$ Luiz Fernando de Sousa Antunes; ${ }^{2}$ Grazieli Azevedo; ${ }^{3}$ Maria Elizabeth Fernandes Correia. \\ ${ }^{1}$ Biólogo e Engenheiro Agrônomo; Mestre em Agronomia - Ciência do Solo; Doutorando do Programa de Pós-graduação em \\ Fitotecnia pela Universidade Federal Rural do Rio de Janeiro (UFRRJ), e-mail: fernando.ufrrj.agro@gmail.com; ${ }^{2}$ Engenheira \\ agrônoma (UFRRJ); ${ }^{3}$ Bióloga (UFRJ); Doutora em Agronomia - Ciência do Solo; Pesquisadora da Embrapa Agrobiologia.
}

RESUMO: A utilização de substratos de qualidade proporciona às plantas cultivadas melhor desempenho e valor comercial. Nesse sentido, o trabalho objetivou avaliar o desenvolvimento do Helliantus annus utilizando o substrato o gongocomposto na fase de muda e posteriormente na fase de vaso. Os tratamentos consistiram de dois substratos orgânicos: gongocomposto e o substrato orgânico comercial Biomix ${ }^{\circledR}$, tendo estes todas as suas propriedades físicas e químicas caracterizadas. $O$ delineamento experimental adotado foi o inteiramente casualizado. No primeiro experimento retirou-se ao acaso oito mudas de girassol por unidade experimental e avaliou-se as massas fresca e seca da parte aérea, massas frescas e seca de raízes, número de folhas, altura das plantas, vigor de muda e estabilidade do torrão. No segundo experimento, que consistiu em 10 plantas para cada substrato, uma por vaso, avaliou-se aos 35 dias após o transplante, as massas seca da parte aérea e de raízes, diâmetro das inflorescências e diâmetro das hastes. Os níveis elevados de nutrientes presentes no gongocomposto, bem como as suas propriedades físicas, propiciaram a obtenção de mudas de qualidade superior em relação às mudas obtidas no substrato Biomix ${ }^{\circledR}$. Na fase de vaso, mesmo sem ocorrer diferenças estatísticas entre os substratos, verificou-se que o gongocomposto apresenta eficiência no desenvolvimento do girassol ornamental.

Palavras-chave: Gongolos, Helianthus annuus, substratos orgânicos, floricultura.

\section{EFFICIENCY OF MILLICOMPOST ON THE ORNAMENTAL SUNFLOWER DEVELOPMENT IN THE PHASES OF SEEDLINGS AND VASE}

ABSTRACT: The use of quality substrates gives cultivated plants better performance and commercial value. In this sense, the work aimed to evaluate the development of 
Helliantus Annus using the substrate millicompost in the seedlings phase and later in the vase stage. The treatments consisted of two organic substrates: millicompost and the Biomix ${ }^{\circledR}$ commercial organic substrate, all of which had their physical and chemical properties characterized. The experimental design was completely randomized. In the first experiment, eight sunflower seedlings per experimental unit were randomly collected and fresh and dry shoot masses, fresh and dry root masses, leaf number, plant height, seed vigor, and stability of the log were evaluated. In the second experiment, which consisted of 10 plants for each substrate, one per vase, the shoot dry weight of shoots and roots, diameter of the inflorescences and diameter of the stems were evaluated at 35 days after transplantation. The high levels of nutrients present in the millicompost, as well as their physical properties, allowed to obtain superior seedlings in relation to the seedlings obtained in the Biomix ${ }^{\circledR}$ substrate. In the potting phase, even without statistical differences between the substrates, it was verified that the millicompost presents efficiency in the development of the ornamental sunflower.

Keywords: Millipedes, Helianthus annuus, organic substrates, floriculture.

\section{INTRODUÇÃO}

O girassol é uma cultura que apresenta ampla adaptabilidade climática, alta tolerância à seca, ao frio e ao calor, tornando-se pouco influenciada pela latitude, altitude e pelo fotoperíodo (ZOBIOLE et al., 2010), além de ser uma planta muito conhecida pelo seu potencial ornamental (SILVA et al., 2011).

O cultivo de plantas em substratos alternativos tem sido cada vez mais empregado em nosso país. Os substratos devem apresentar baixo custo, disponibilidade nas proximidades da região de consumo, apresentar suficiente teor de nutrientes, boa capacidade de troca catiônica, permitir aeração e retenção de umidade, bem como, favorecer a atividade fisiológica das raízes (OLIVEIRA et al., 2008).

A escolha de um substrato adequado ao cultivo de plantas em vaso requer o prévio conhecimento das suas características químicas e físicas, as quais podem interferir no crescimento e desenvolvimento da planta. Ademais, um substrato orgânico de qualidade pode ser produzido a partir de resíduos agrícolas e urbanos localmente disponíveis, com baixo custo de produção, representando um dos elementos chave para o cultivo de flores de corte aos pequenos produtores, que não 
demandam de grandes áreas para produzir e ainda tem-se a possibilidade de geração de renda alternativa, fixando a mão de obra no campo.

O gongocomposto é um substrato de origem orgânica ainda pouco conhecido e seu nome advém do processo de gongocompostagem, que consiste na transformação de resíduos vegetais lignocelulósicos em composto orgânico estável, - qual é mediado pela atividade biológica de diplópodes, organismos decompositores da fauna do solo, popularmente conhecidos como gongolos ou piolhos-de-cobra (ANTUNES, 2017).

Embora as pesquisas sejam pontuais no mundo com a utilização do gongocomposto como substrato, elas trazem resultados excelentes, tais como a produção de pimenta vermelha em vasos na Índia (ANILKUMAR et al., 2012) e aqui no Brasil, com a produção mudas de alface lisa (ANTUNES et al., 2016) e alface crespa (ANTUNES, 2017). Recentemente, Antunes et al. (2018) avaliaram a qualidade das mudas de alface crespa produzidas com gongocompostos oriundos de diferentes tempos de gongocompostagem e confirmaram que a qualidade das mudas transplantadas a campo foi capaz de influenciar positivamente no desempenho produtivo da cultura da alface.

Neste sentido, como não há registros do uso do gongocomposto na área ornamental, o objetivo geral deste trabalho foi avaliar a eficiência do gongocomposto como substrato no desenvolvimento de mudas de girassol ornamental anão de jardim e posteriormente a fase de desenvolvimento em vasos utilizando do mesmo substrato, que constitui a fase futura à comercialização como planta ornamental.

\section{MATERIAL E MÉTODOS}

Experimento 1 - produção das mudas

Sementes de girassol anão (Helianthus annus L.) da empresa Isla sementes Ltda foram colocadas para germinar em mini bandejas de poliestireno expandido contendo 20 células cada, com capacidade para acondicionar $35 \mathrm{~cm}^{3}$ de substrato.

Os tratamentos consistiram de dois substratos orgânicos: 1) Gongocomposto, o qual foi produzido de acordo com a metodologia adotada por Antunes (2017), 
utilizando resíduos vegetais secos, cuja mistura foi constituída por folhas de Bauhinia sp. (folhas de pata-de-vaca), Paspalum notatum (aparas de grama), Musa $s p$. (folhas de bananeira) e aparas de papelão. A proporção em volume dos materiais foi, respectivamente, de $40 \%, 30 \%, 20 \%$ e 10\%. O gongocomposto foi obtido em 180 dias, sendo peneirado em malha de $2 \mathrm{~mm}$ e posteriormente posto em uso; 2) Biomix ${ }^{\circledR}$ orgânico, constituído por pó ou fibra de coco, casca de pinus moída e compostada, Bokashi (aditivo orgânico com macro e micronutrientes) e composto orgânico fórmula Biomix ${ }^{\circledR}$.

Aos 21 dias após a semeadura, retirou-se ao acaso oito mudas de girassol ornamental por unidade experimental e foram avaliados os seguintes parâmetros: vigor da muda (VM), estabilidade do torrão (ET), massa fresca da parte aérea (MFPA), massa seca da parte aérea (MSPA), massa fresca de raízes (MFR), massa seca de raízes (MSR), número de folhas (NF) e altura das plantas (AP), que compreende o ponto de inserção da raiz até o ápice foliar.

A metodologia para determinação do vigor das mudas (VM) é uma metodologia adaptada de Franzin et al. (2005), classificando como: Nota 1: ótimo vigor, número de folhas $\geq 4$, altura maior que $5 \mathrm{~cm}$ e ausência visual de deficiência nutricional; Nota 2: vigor bom, número de folhas $\geq 4$, altura $\geq 5 \mathrm{~cm}$ e início de amarelado não proeminente nas folhas basais; Nota 3: vigor regular, número de folhas $\geq 4$, altura $\geq 5 \mathrm{~cm}$; deficiência nutricional expressa por um amarelecimento proeminente que se estende para além das folhas basais ou outro sintoma intrínseco; Nota 4: vigor ruim, deficiência nutricional bem destacada, expressa por problemas na altura ( $\leq 5 \mathrm{~cm}$ ), número de folhas reduzido ( $\leq 4$ folhas) e amarelecimento intenso ou outro sintoma intrínseco.

Para estabilidade do torrão (ET) é uma metodologia adaptada de Freitas et al. (2010) e Gruszynski (2002), classificando como: Nota 1: Baixa estabilidade, 50\% ou mais do torrão fica retido no recipiente na retirada da muda e o torrão não permanece coeso; Nota 2: Entre 30 a $50 \%$ do torrão fica retido no recipiente na retirada da muda, porém o torrão não permanece coeso; Nota 3: Regular, entre 15 a $30 \%$ do torrão fica retido no recipiente na retirada da muda, porém não permanece coeso; Nota 4: Boa estabilidade, o torrão é destacado completamente do recipiente 
com até $90 \%$ de coesão e perda máxima de até $10 \%$ do substrato; Nota 5: Ótima estabilidade, o torrão é destacado completamente do recipiente e mais de $90 \%$ dele permanece coeso, com perdas inferiores a $10 \%$ de substrato.

Para a determinação das massas secas, a parte aérea e as raízes das plantas foram acondicionadas separadamente em sacos de papel e mantidas em estufa de circulação de ar forçada a $65^{\circ} \mathrm{C}$ por 72 horas.

O delineamento experimental utilizado foi o inteiramente casualizado, com cinco repetições para cada tratamento. Os dados foram submetidos à análise de variância pelo teste $F(p \leq 0,05)$, utilizando o programa estatístico SISVAR (FERREIRA, 2008).

\section{Caracterização Física e Química dos Substratos}

Quanto às características físicas dos substratos, foram avaliados os seguintes parâmetros: macroporosidade, microporosidade, porosidade total, capacidade de retenção de água e densidade volumétrica, através da metodologia adaptada de Silva (1998) e MAPA (2008).

Para caracterizar os substratos quanto às suas características químicas, foram encaminhadas amostras de cada tratamento ao Laboratório de Química Agrícola da Embrapa Agrobiologia, para determinação dos teores de P, K, Ca e Mg, de acordo com a metodologia descrita por Embrapa (2005). A determinação dos teores de $\mathrm{N}$ e $\mathrm{C}$ foi feito no analisador elementar ( $\mathrm{CHN})$, conhecido também como método de Dumas (NELSON; SOMMERS, 1996).

As análises de $\mathrm{pH}$ foram realizadas em solução de água destilada (5:1 v/v) e a condutividade elétrica foi determinada no mesmo extrato aquoso obtido para a medição do $\mathrm{pH}$, de acordo com o método descrito por MAPA (2008). Foram realizadas triplicatas para todas análises supracitadas.

\section{Experimento 2 - Desenvolvimento das Mudas em Vasos}

As mudas de girassol ornamental destinadas ao cultivo em vasos foram transplantadas 21 dias após a semeadura (DAS) em vasos plásticos de cor cerâmica 
№ 01 , com capacidade para $400 \mathrm{~cm}^{3}$. Os tratamentos consistiram dos mesmos substratos orgânicos utilizados no experimento 1.

Os vasos foram dispostos aleatoriamente em uma mesa de madeira, perfazendo 20 vasos, sendo 10 vasos contendo o gongocomposto e 10 vasos contendo o Biomix ${ }^{\circledR}$ orgânico, cada qual com uma planta. As plantas eram irrigadas duas vezes por dia com o auxílio de um regador comum. Semanalmente foram adicionados 3,5 gramas de torta de mamona sob a superfície dos vasos, a fim de fazer a manutenção nutricional dos girassóis.

Aos 35 dias após o transplante em vaso, foram avaliados os seguintes parâmetros: massa seca da parte aérea (MSPA) - compreendendo as folhas, hastes e inflorescências quando existentes; massa seca de raízes (MSR); diâmetro das inflorescências (DI) quando existentes e diâmetro da haste (DH). Para a determinação das massas secas, as partes aéreas e as raízes das plantas foram acondicionadas separadamente em sacos de papel e mantidas em estufa de circulação de ar forçada a $65^{\circ} \mathrm{C}$ por 72 horas.

O delineamento experimental adotado foi o inteiramente casualizado, com dez repetições para cada tratamento. Os dados foram submetidos à análise de variância pelo teste $F(p \leq 0,05)$, utilizando o programa estatístico SISVAR (FERREIRA, 2008).

\section{RESULTADOS}

Ocorreram diferenças significativas $(p<0,05)$ em todos os parâmetros analisados na fase de desenvolvimento das mudas de girassol, exceto para a estabilidade do torrão (ET), as quais se mantiveram iguais (Figuras 1-A e 1-B). As mudas de girassol ornamental desenvolvidas no substrato gongocomposto apresentaram um padrão de desenvolvimento muito superior quando comparado às mudas desenvolvidas no substrato orgânico Biomix ${ }^{\circledR}$ orgânico, de modo que os valores médios das massas frescas da parte aérea e das raízes foram 148,08\% e 78\% maiores, respectivamente. (Figura 1-A). 

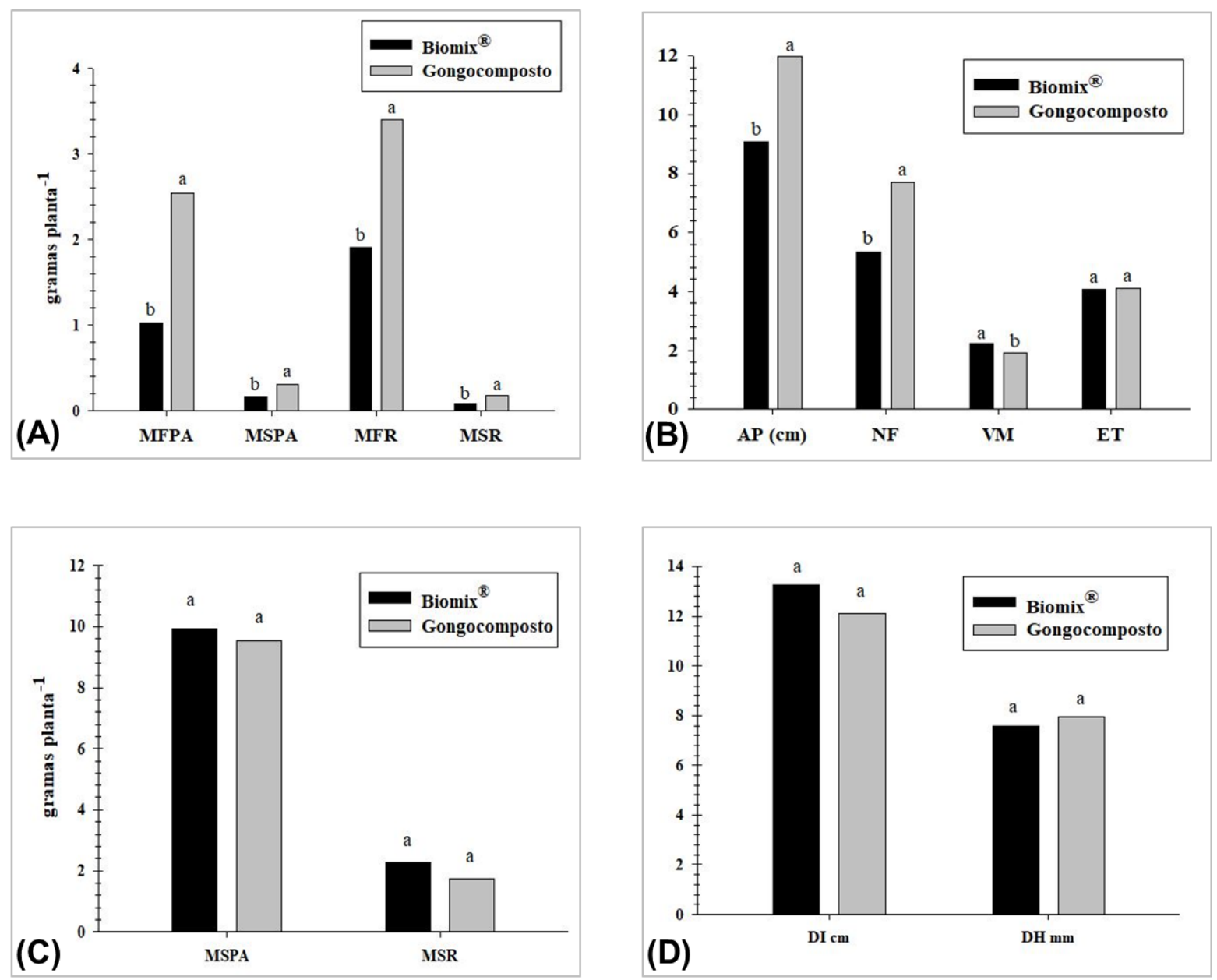

Figura 1. (A) Valores médios de massa fresca da parte aérea (MFPA), massa seca da parte aérea (MSPA), massa fresca das raízes (MFR) e massa seca das raízes (MSR) de mudas girassol ornamental desenvolvidas em substratos orgânicos aos 21 dias após semeadura.; (B) Valores médios de altura de planta (AP), número de folhas por planta (NF), vigor de muda (VM) e estabilidade do torrão (ET) de mudas girassol ornamental; (C) Valores médios de massa seca parte aérea e raízes das plantas de girassol ornamental após 35 dias de transplante; (D) Valores médios do diâmetro da inflorescência (DI) e diâmetro da haste (DH), das plantas de girassol ornamental.

Figure 1. (A) Mean values of shoot fresh mass (MFPA), dry shoot mass (MSPA), fresh root mass (MFR) and root dry mass (DMW) of ornamental sunflower seedlings grown on organic substrates at 21 days after sowing .; (B) Mean values of plant height (AP), number of leaves per plant (NF), seedling vigor (VM) and stability of clod (ET) of ornamental sunflower seedlings; (C) Mean values of shoot dry mass and roots of ornamental sunflower plants after 35 days of transplantation; (D) Mean values of inflorescence diameter (DI) and stem diameter (DH) of ornamental sunflower plants. 
As massas secas da parte aérea e das raízes seguiram o mesmo comportamento, sendo $89,32 \%$ e $102,31 \%$ maiores nas mudas contendo o substrato gongocomposto em relação ao substrato Biomix ${ }^{\circledR}$ orgânico (Figura 1-A). O substrato Biomix ${ }^{\circledR}$ orgânico apresentou valores médios estatisticamente inferiores ao substrato gongocomposto para os parâmetros de altura de plantas, número de folhas e vigor da muda (Figura 1-B). Os dois substratos registraram resultados semelhantes em relação à estabilidade do torrão, não diferindo entre si ( $p>0,05)$.

Os percentuais de macroporos e porosidade total foram maiores no gongocomposto, em relação ao substrato Biomix ${ }^{\circledR}$ orgânico. O substrato Biomix ${ }^{\circledR}$ orgânico apresentou uma capacidade de retenção de água um pouco maior que o gongocomposto. A densidade volumétrica também apresentou valor superior no substrato Biomix ${ }^{\circledR}$ orgânico quando comparado ao gongocomposto, duas vezes menos denso (Tabela 1).

Tabela 1. Análises físicas dos substratos avaliados: percentuais de microporosidade, macroporosidade, porosidade total, capacidade de retenção de água à tensão de $10 \mathrm{~cm}($ CRA10 $\mathrm{cm})$ e densidade volumétrica. Table 1. Physical analysis of substrates evaluated: percentage of microporosity, macroporosity, total porosity, water retention capacity at $10 \mathrm{~cm}(C R A 10 \mathrm{~cm})$ and volumetric density.

\begin{tabular}{|c|c|c|c|c|c|}
\hline \multirow{2}{*}{ Substratos } & Macroporos & Microporos & Porosidade total & \multirow{2}{*}{$\begin{array}{c}\text { CRA }_{10 \mathrm{~cm}} \\
\mathrm{~mL} 50 \mathrm{~cm}^{-3}\end{array}$} & \multirow{2}{*}{$\begin{array}{c}\text { Densidade } \\
\text { Volumétrica } \\
\mathrm{g} \mathrm{cm}^{-3}\end{array}$} \\
\hline & ------------. & ------ (\%) -- & ------------------- & & \\
\hline Biomix $^{\circledR}$ & $12,77 \mathrm{~b}$ & $62,07 \mathrm{a}$ & $74,85 \mathrm{~b}$ & $31,04 \mathrm{a}$ & $0,45 \mathrm{a}$ \\
\hline Gongocomposto & $31,24 \mathrm{a}$ & $60,45 \mathrm{~b}$ & $91,70 \mathrm{a}$ & $30,23 \mathrm{~b}$ & $0,20 \mathrm{~b}$ \\
\hline CV (\%) & 5,97 & 1,14 & 1,64 & 1,14 & 1,25 \\
\hline
\end{tabular}

Médias seguidas pela mesma letra na coluna não diferem pelo teste de $F(p<0,05)$.

Os valores de $\mathrm{pH}$ e condutividade elétrica (Tabela 2) foram estatisticamente diferentes $(p<0,05)$ entre os substratos avaliados, sendo estes um pouco mais elevados para o gongocomposto. Os teores de nutrientes contidos nos substratos diferenciaram-se significativamente $(p<0,05)$, sendo os valores mais elevados registrados para o substrato gongocomposto. 
Tabela 2. Análises do potencial hidrogeniônico $(\mathrm{pH})$, condutividade elétrica $(\mathrm{CE})$, relação $\mathrm{C} / \mathrm{N}$, conteúdo de carbono total e teores de macronutrientes totais dos substratos avaliados na produção de mudas de girassol ornamental.

Table 2. Analysis of the hydrogenation potential $(\mathrm{pH})$, electrical conductivity $(E C), C / N$ ratio, total carbon content and total macronutrient contents of the substrates evaluated in the production of ornamental sunflower seedlings.

\begin{tabular}{|c|c|c|c|c|c|c|c|c|c|}
\hline \multirow{2}{*}{ Substratos } & \multirow{2}{*}{$\mathrm{pH}$} & \multirow{2}{*}{$\begin{array}{c}\text { CE } \\
\mathrm{dS} \mathrm{m}^{-1}\end{array}$} & \multirow{2}{*}{$\begin{array}{c}\text { Relação } \\
\text { C/N }\end{array}$} & $\mathbf{C}$ & $\mathbf{N}$ & $\mathbf{P}$ & $\mathbf{K}$ & $\mathrm{Ca}$ & Mg \\
\hline & & & & \multicolumn{6}{|c|}{ 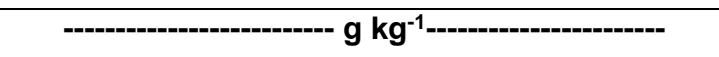 } \\
\hline Biomix $^{\circledR}$ & $6,69 \mathrm{~b}$ & $0,49 \mathrm{~b}$ & $41,93 \mathrm{a}$ & $325,04 \mathrm{~b}$ & $7,76 \mathrm{~b}$ & $1,53 \mathrm{~b}$ & $2,32 b$ & $9,03 \mathrm{~b}$ & $2,73 b$ \\
\hline Gongocomposto & $7,34 \mathrm{a}$ & $0,69 a$ & $15,24 b$ & $354,34 \mathrm{a}$ & $23,25 \mathrm{a}$ & $2.96 \mathrm{a}$ & $4.78 \mathrm{a}$ & $31,69 \mathrm{a}$ & $4,48 \mathrm{a}$ \\
\hline CV (\%) & 0,85 & 2,93 & 2,02 & 1,38 & 1,46 & 7,38 & 2,89 & 7,99 & 6,90 \\
\hline
\end{tabular}

Médias seguidas pela mesma letra na coluna não diferem pelo teste de $F(p<0,05)$.

Após o transplante das mudas de Helliantus annus L. para os vasos, as plantas de girassol ornamental se desenvolveram sem apresentar problemas fitossanitários ou sintomas de deficiência nutricional, não diferindo estatisticamente ( $p>0,05)$ nos parâmetros de massa seca da parte aérea e raízes (Figura 1-C).

Os diâmetros e inflorescências dos girassóis também não exibiram diferenças estatísticas $(p>0,05)$, embora as inflorescências dos girassóis desenvolvidas no substrato Biomix ${ }^{\circledR}$ orgânico foram $1,16 \mathrm{~cm}$ maiores que no substrato gongocomposto (Figura 1-D).

\section{DISCUSSÃO}

O teor de nitrogênio presente no substrato gongocomposto foi três vezes maior quando comparado ao substrato comercial Biomix ${ }^{\circledR}$ orgânico (Tabela 2), proporcionando um melhor desenvolvimento na fase de muda do girassol ornamental. Antunes et al. (2016) verificaram que o conteúdo de nutrientes como cálcio, magnésio e fósforo, bem como as características físico-químicas e físicas do composto gerado por diplópodes, foram eficientes como substrato na produção de mudas de alface, corroborando com os resultados alcançados neste trabalho, proporcionando mudas de girassol ornamental com qualidade superior às mudas obtidas com substrato orgânico comercial Biomix ${ }^{\circledR}$ orgânico (Figura 2-B).

Segundo Tajovský et al. (1992), os excrementos dos diplópodes são constituídos por tecidos vegetais não digeridos, partículas minerais, microrganismos, 
além de possuir valores de $\mathrm{pH}$ mais elevados, tal como maior capacidade de retenção de água. Fato que comprova maiores valores de porosidade total e pH no substrato gongocomposto (Tabelas 1 e 2).

De acordo com Loureiro et al. (2011), os diplópodes são capazes de processar material vegetal com elevada relação $\mathrm{C} / \mathrm{N}$, reduzindo sua massa, diminuindo a relação $\mathrm{C} / \mathrm{N}$ e liberando nutrientes ao solo. Portanto, como observado na (Tabela 2), o substrato orgânico comercial Biomix ${ }^{\circledR}$ orgânico apresentou uma relação $\mathrm{C} / \mathrm{N}$ superior quando comparado ao substrato gongocomposto. Isso é decorrência dos componentes que são utilizados na sua formulação, tais como a casca de pinus, de alta relação $\mathrm{C} / \mathrm{N}$.

Stevenson (1986), relatou que uma relação $\mathrm{C} / \mathrm{N}$ maior que 30 leva à imobilização de N; entre 20 e 30 a mineralização é igual à imobilização e com C/N menor que 20 predomina a mineralização. Observando a (Tabela 2), o substrato

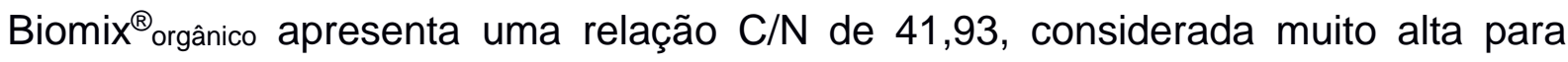
uma adequada mineralização dos nutrientes, podendo haver, pelo menos inicialmente, imobilização do $\mathrm{N}$ mineralizado. O substrato gongocomposto apresenta uma relação $\mathrm{C} / \mathrm{N}$ de 15,24, estando em uma faixa em que predomina a mineralização de nutrientes, por estar mais estabilizado.

Gonçalves; Poggiani (1996) estabeleceram escalas de valores para a interpretação das características químicas de substratos para plantas, tais como os níveis adequados de macronutrientes. A concentração de fósforo considerada adequada varia de 0,40 a 0,80 $\mathrm{g} \mathrm{kg}^{-1}$, estando acima dos níveis considerados adequados nos dois substratos, sendo $1,53 \mathrm{~g} \mathrm{~kg}^{-1}$ para o substrato comercial

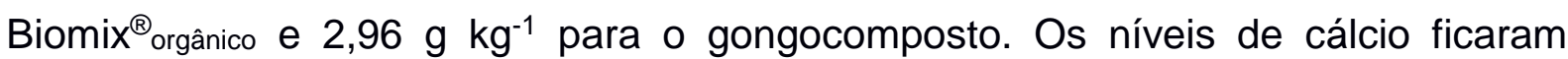
acima dos níveis considerados adequados (2,00 a 4,00 $\mathrm{g} \mathrm{kg}^{-1}$ ) para os dois substratos, sendo que o gongocomposto apresentou valores bem acima dos recomendados, sendo $31,69 \mathrm{~g} \mathrm{~kg}^{-1}$. Os teores de magnésio ficaram abaixo do recomendado para os dois substratos $\left(6,07\right.$ a $\left.12,16 \mathrm{~g} \mathrm{~kg}^{-1}\right)$.

O potássio $(\mathrm{K})$ constitui-se em um elemento fundamental no desenvolvimento dos vegetais, pois o mesmo é capaz de incrementar a translocação de carboidratos nas plantas, aprimora a utilização de água pelas mesmas, além disso, na presença 
de potássio a utilização de nitrogênio é potencializada (FOLONI, et al., 2013). Os teores de potássio contidos no substrato gongocomposto (Tabela 2) proporcionaram o melhor desenvolvimento na fase de mudas do girassol.

Para os valores de pH (Tabela 2), os dois substratos apresentaram níveis superiores às faixas ideais, que de acordo com Gonçalves; Poggiani (1996), a faixa ideal de pH compreende valores de 5,5 a 6,5. No entanto, não ocorreram problemas quanto ao desenvolvimento das mudas, principalmente no substrato gongocomposto, o qual registrou $u m \mathrm{pH}$ de 7,34 e as melhores médias nos parâmetros avaliados na fase de mudas (Figuras 1-A, 1-B e 2-B).

Com base na Tabela 2, observa-se que os dois substratos apresentaram valores de condutividade elétrica baixa. Os valores de CE entre 2,0 a 4,0 dS m${ }^{-1}$ são considerados altos para substratos, valores de 1,0 a 2,0 dS $\mathrm{m}^{-1}$ são normais e menores que 1,0 dS $\mathrm{m}^{-1}$ são considerados baixos (ARAÚJO NETO et al., 2009). Portanto, os dois substratos apresentaram concentrações baixa de sais.

Rezende et. al. (2013) avaliaram o crescimento de agrião em resposta atividade de minhocas Chibuibari e Trigoniulus corallinus em substrato à base de solo e composto orgânico, onde verificaram que o composto produzido por Trigoniulus corallinus promoveu maior massa fresca e seca do agrião, corroborado com os mesmos resultados no presente trabalho para os parâmetros de massa fresca e seca de parte aérea e raízes (Figura 1-A).

Embora o substrato gongocomposto tenha apresentado porosidade total superior ao Biomix ${ }^{\circledR}$ orgânico, ele atende à recomendação estabelecida por Carrijo et al. (2002), a qual deve estar acima de 85\%. Drzal et al. (1999) e Schmitz et al. (2002) afirmam que o conteúdo de água retido no substrato é diretamente correlacionado com a distribuição dos poros por tamanho. Segundo os primeiros autores, os macroporos não retêm água sob força gravitacional, sendo estes, por conseguinte, responsáveis pela aeração das raízes.

Ballester-Olmos (1992) explica que são os microporos aqueles responsáveis pela retenção de água. A capacidade de retenção de água de um substrato exerce papel fundamental no fornecimento de água às plantas. Gonçalves; Poggiani (1996) consideram como níveis adequados de capacidade de retenção de água, valores 
entre 20 - $30 \mathrm{~mL} 50 \mathrm{~cm}^{-3}$. Deste modo, os dois substratos se enquadram nos níveis de retenção de água descritos por estes autores (Tabela 1).

O diâmetro de inflorescência é, juntamente com a altura de plantas, a variável que indica o valor comercial da planta de girassol ornamental. Assim, no presente trabalho (Figura 3), verifica-se que, ao final do ciclo da cultura, que as inflorescências obtidas nos dois tratamentos foram viáveis comercialmente, já que, de acordo com a Sakata Seed Corporation (2003), os valores de diâmetro de inflorescência devem estar, em média, entre 10,0 e 15,0 cm de bráctea a bráctea. Dessa forma, os girassóis apresentaram inflorescências viáveis à comercialização, com diâmetros acima de $12 \mathrm{~cm}$, conforme pode ser observado na Figura 2-C e 2-D.
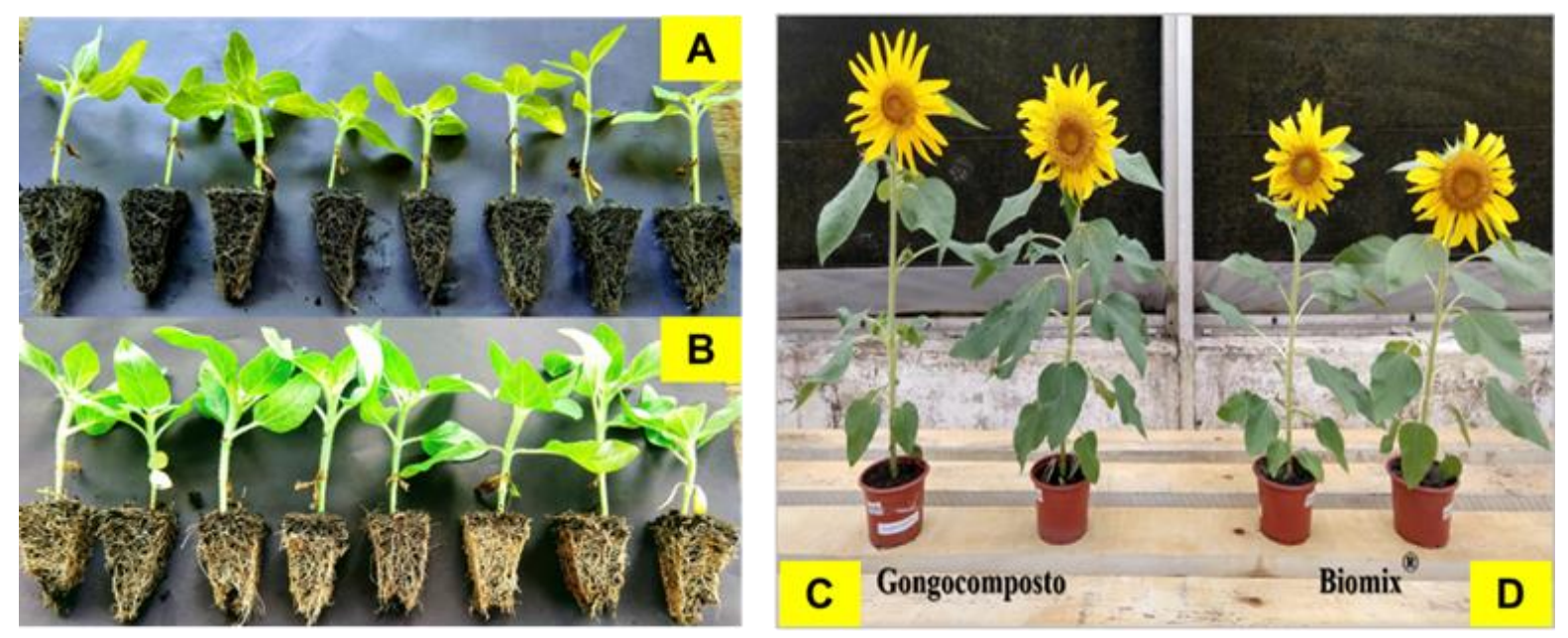

Figura 2. Mudas girassol ornamental desenvolvidas em substratos orgânicos aos 21 dias após semeadura: (A) Substrato Biomix ${ }^{\circledR}$; (B) Gongocomposto. Plantas de girassol ornamental com 35 dias após transplante desenvolvidas nos substratos orgânicos gongocomposto $(C)$ e Biomix ${ }^{\circledR}(D)$.

Figure 2. Ornamental sunflower seedlings developed on organic substrates at 21 days after sowing: $(A)$ Biomix® substrate; (B) millicompost. Ornamental sunflower plants with 35 days after transplantation developed on organic substrates millicompost (C) and Biomix® (D).

\section{CONCLUSÕES}

O gongocomposto apresenta eficiência no desenvolvimento das mudas de girassol ornamental, proporcionando mudas de excelente qualidade, as quais ao serem transplantadas em vasos, alcançam a qualidade desejada à comercialização. 


\section{AGRADECIMENTOS}

À Embrapa Agrobiologia e toda sua equipe pelo apoio à pesquisa desenvolvida.

\section{REFERÊNCIAS}

ANILKUMAR, C.; IPE, C.; BINDU, C.; CHITRA, C.R.; MATHEW, P.J.; KRISHNAN, P.N. Evaluation of millicompost versus vermicompost. Current Science, v.103, n.2, 25 july 2012.

ANTUNES, L. F. S; SCORIZA, R. N.; FRANÇA, E. F.; SILVA, D. G.; CORREIA, M. E. F.; LEAL, M. A. A.; ROUWS, J. R. C. Desempenho agronômico da alface crespa a partir de mudas produzidas com gongocomposto. Revista Brasileira de Agropecuária Sustentável (RBAS), v.8, n.3, p.57-65, setembro, 2018.

ANTUNES, L. F. S. Produção de gongocompostos e sua utilização como substrato para mudas de alface. 2017. 73f. Dissertação (Mestrado em Agronomia - Ciência do Solo) - Universidade Federal Rural do Rio de Janeiro, 2017.

ANTUNES, L.F.S.; SCORIZA, R.N.; SILVA, D.G.; CORREIA, M.E.F. Production and efficiency of organic compost generated by millipede activity. Ciência Rural, v.46, p.815-819, 2016.

ARAÚJO NETO, S.E.; AZEVEDO, J.M.A.; GALVÃO, R.O.; OLIVEIRA, E.B.L.; FERREIRA, R.L.F. Produção de muda orgânica de pimentão com diferentes substratos. Ciência Rural, v.39, n.5, 2009.

BALLESTER-OLMOS, J.F. Substratos para el cultivo de plantas ornamentales. Valencia: Instituto Valenciano de Investigaciones Agrarias, 1992. 44 p. (Hojas divulgadoras, 11).

CARRIJO, O.A.; LIZ, R.S.; MAKISHIMA, N. Fibra da casca do coco verde como substrato agrícola. Horticultura Brasileira, Brasília, v. 20, n.4, p.533-535, 2002. 
DRZAL, M.S.; FONTENO W.C.; CASSEL D.K. Pore fraction analysis: a new tool for substrate testing. Acta Horticulture, v.148, p. 43-53, 1999.

FERREIRA, D.F. SISVAR: um programa para análises e ensino de estatística. Revista Symposium (Lavras), v.6, p.36-41, 2008.

FOLONI, J.S.S. et al. Adubação de cobertura na batata-doce com doses combinadas de nitrogênio e potássio. Cadernos de agroecologia - ISSN 22367934, Londrina, v.34, n.1, p.111-222, 2013.

FRANZIN, S.M.; MENEZES, N.L.; GARCIA, D.C.; SANTOS, O.S. Efeito da qualidade das sementes sobre a formação de mudas de alface. Horticultura Brasileira, Brasília, v.23, n.2, p.193-197, 2005.

FREITAS, T. A. S.; BARROSO, D. G.; SOUZA, L. S.; CARNEIRO, J. G. A.; PAULINO, G; M. Produção de mudas de eucalipto com substratos para sistema de blocos. Revista Árvore, Viçosa, v. 34, n. 5, p. 761-770, 2010. http://dx.doi.org/10.1590/S0100-67622010000500001.

GONÇALVES, J.L.M.; POGGIANI, F. Substratos para produção de mudas florestais. In: CONGRESSO LATINO AMERICANO DE CIÊNCIA DO SOLO, 13., Águas de Lindóia, 1996. Resumos. Piracicaba, Sociedade Latino Americana de Ciência do Solo, 1996. CD-Rom.

GRUSZYNSKI, C. Resíduo agro-industrial "casca de tungue" como componente de substrato para plantas. Porto Alegre: UFRGS. 2002. p. 41. (Tese mestrado).

LOUREIRO, N.F.; BIANCHI, M.O.; CORREIA, M.E. F. Caracterização dodesenvolvimento pós-embrionário do diplópode Trigoniulus corallinus (Gervais). In: SEMANA CIENTÍFICA JOHANNA DÖBEREINER, 11., 2011, Seropédica, Anais...Seropédica: Embrapa Agrobiologia, 2011.

MINISTÉRIO DA AGRICULTURA, PECUÁRIA E ABASTECIMENTO (MAPA). Instrução Normativa SDA N. 31 . Diário Oficial da União- Seção 1, 24 de outubro de 2008. Alteração dos subitens 3.1.2, 4.1 e 4.1 .2 da Instrução Normativa $n . \stackrel{0}{17}$ de 
21/05/2007. Métodos Analíticos Oficiais para Análise de Substratos para Plantas e Condicionadores de Solo. Brasília, 2008.

NELSON, D.W.; SOMMERS, L.E. Total carbon, organic carbon, and organic matter. In: SPARKS, D.L.; PAGE, A. L.; HELMKE, P. A.; LOEPPERT, R. H.; SOLTANPOUR, P. N.; TABATABAI, M. A.; JOHNSTON, C.T.; M. E. SUMNER, M. E. Methods of Soil Analysis. Madison: SSSA and ASA. 1996. 983 p.

OLIVEIRA, A.B.; HERNANDEZ, F.F.F.; ASSIS JR., R.N. Pó de coco verde, uma alternativa de substrato na produção de mudas de berinjela. Revista Ciência Agronômica, v. 39, n. 01, p. 39-44, 2008.

REZENDE, M.F.L.; SOUZA. K.G.; PINTO, G.P.; KUSDRA, J.F.; FIUZA, S.S. 15219 Crescimento de agrião em substrato à base de composto orgânico submetido à atividade de Chibui bari (Annelida: Oligochaeta) e Trigoniulus corallinus (Diplopoda: Spirobolida). Cadernos de Agroecologia, [S.I.], v.8, n.2, 2013. RICE, G. Rays of sunshine. Garden London, London, v.121, n.8, p.490-495, 1996.

SAKATA SEED CORPORATION. Sakata's reliable seeds: flower seed catalogue 2001-2003. Bragança Paulista: Sakata Sementes Agroflora, 2003. p.99.

SCHMITZ, J.A.K.; SOUZA, P.V.D.; KÄMPF A.N. Propriedades químicas e físicas de substratos de origem mineral e orgânica para o cultivo de mudas em recipientes. Ciência Rural v.32. p. 937-944, 2002.

SILVA, M.R. da. Caracterização morfológica, fisiológica e nutricional de mudas de Eucalyptos grandis Hill ex Maiden submetidas a diferentes níveis de estresse hídrico. 1998. 105p. Dissertação (Mestrado em Engenharia Florestal/Silvicultura) Universidade Federal do Paraná, Curitiba, 1998.

STEVENSON, F.J. Cycles of soil - carbon, nitrogen, phoshporus, sulfur and micronutrients. John Wiley \& Sons, NY, 1986. 380p. 
TAJOVSKÝ, K.; ŠANTRŮČKOVÁ, H.; HÁNĚL, L.; BALÍK, V.; LUKEŠOVÁ, A. Decomposition of faecal pellets of the millipede Glomeris hexasticha (Diplopoda) in forest soil. Pedobiologia, v.36, p.146-158, 1992.

ZOBIOLE, L.H.S.; CASTRO, C.; OLIVEIRA, F.A.; OLIVEIRA JÚNIOR, A. Marcha de absorção de macronutrientes na cultura do girassol. Revista Brasileira de Ciência do Solo, v.34, p.425-433, 2010. 